\title{
Mima polymorpha infection
}

\author{
J. BRODIE AND A. HENDERSON \\ From the Laboratory, City Hospital, Aberdeen
}

SYNOPSIS Two cases of human infection by Mima polymorpha are described. From these cases, and from the literature, it is concluded that this species is heterogeneous with respect to its biochemical properties. From comparative studies it is concluded that the genus Mima is unrelated to the genus Moraxella or to Bacterium anitratum.

\section{BACTERIOLOGICAL FINDINGS IN TWO CASES OF HUMAN INFECTION}

As early as 1936, epidemics and sporadic cases of meningitis had been observed in which Gramnegative diplococci were found but which differed from the Neisseriae in growing on nutrient agar (Sen, 1936). In 1939, de Bord found that $33 \%$ of male patients, thought to be suffering from gonorrhoea because Gram-negative diplococci were present in the discharge, had in fact not been harbouring $N$. gonorrhoeae but organisms of a group unrelated to the Neisseriae. Accordingly, in 1942, he compiled a new tribe which he named the Mimeae, and which he divided into three genera named Mima, Herellea, and Colloides. These genera were apparently well marked from each other by indole production, citrate utilization, and the reduction of potassium nitrate to nitrite. The group as a whole was thought to be a non-oxidase producer, but de Bord found an oxidase-producing variant of $M$. polymorpha. In 1945, Deacon found that not only were some strains of Mima polymorpha atypical in producing oxidase but also in utilizing citrate or reducing nitrates. De Bord also noted in 1943 that, while typical species of Mima did not ferment carbohydrates, some strains from the vagina and conjunctiva might do so and, in this connexion, he investigated the action of the bacteria on glucose, maltose, sucrose, mannitol, dulcitol, salicin, and dextrin only.

Evidence of the pathogenic potentialities of the tribe grew. De Bord isolated Mima polymorpha var. oxidans, Herellea vaginicolia, and Colloides anoxydana from clinically normal conjunctivas and vaginas, but, in addition, he and Deacon (1945) isolated these from 'gonorrhoea', septic war wounds, and from brain tissue following injury. In 1948 de

Received for publication 5 May 1962.
Bord described the isolation of Mima polymorpha from the cerebrospinal fluid of a man with meningitis. Townsend, Hersey, and Wilson (1954) isolated Mima polymorpha from a patient with meningitis who died of the Waterhouse-Friederichsen syndrome. A contact of this man also developed meningitis, and he, too, yielded Mima polymorpha. The graver pathogenic possibilities of the organism were discussed by Faust and Hood (1949) who described the case of a woman who died of septicaemia after an illness lasting only 42 hours and from whom Mima polymorpha var. oxidans was recovered. Pike, Schulze, and McCullough (1951) described a boy of 6 years who had an operation for a congenital heart defect and six months later developed a low-grade pyrexia which persisted for two years, after which Mima polymorpha var. oxidans was recovered from blood and bone marrow cultures.

De Torregrosa and Ortiz (1961) have reviewed much of the literature concerning Mima polymorpha, and emphasized the importance of thorough biochemical investigation of Gram-negative cocci to avoid confusion with various species of Neisseria. Three of their five cases in young children suffered from meningitis and two from septicaemia. Of their fatal cases, two had meningitis and one had otitis media and pneumonia due to Mima polymorpha. Two of these instances are of particular interest. A female premature infant of $4 \mathrm{lb}$. $9 \mathrm{oz}$. developed meningitis on the fourth day of life and died 18 days later of meningitis and bronchopneumonia despite treatment with chloramphenicol, streptomycin, and sulphadiazine. The second case was the twin sister of the foregoing, and weighed $4 \mathrm{lb}$. $6 \mathrm{oz}$. She first developed symptoms one day after her sister, at the age of 5 days. She died at the age of 14 days, despite treatment with oxytetracycline, chloramphenicol, and polymyxin B. Mima polymorpha was isolated from the blood and from the purulent aural dis- 
charge. These cases are of interest as they appear to indicatecase-to-case transmission as in the infections reported by Townsend et al.

That the members of the genus Herellea also are pathogenic is shown by Sorrell and White (1953) and of Schuldberg (1953). Sorrell and White published the case of a 39-year-old man who was admitted to hospital suffering from acute bacterial endocarditis. The strain isolated differed from a typical Herellea sp. in giving a positive methyl red reaction and producing a yellow pigment. Schuldberg described the case of an 18-month-old girl who died of leptomeningitis with haemorrhage into the adrenal cortices. This strain was atypical in causing betahaemolysis on blood agar.

Two recent instances of the recovery of Mima spp. from wound infections in Aberdeen are now described.

CASE 1 A 29-year-old man suffering from Hodgkin's disease had his gall bladder removed on account of cholelithiasis; the wound became infected; coagulasepositive staphylococci and Mima polymorpha were isolated on culture.

CASE 2 A 57-year-old man was admitted to hospital after a history of osteomyelitis of the femur. From swabs taken from the sinus coagulase-positive staphylococci and Mima polymorpha were recovered on three occasions.

The organisms isolated from cases 1 and 2 were predominantly of coccal type; any tendency to become bacillary was minimal. Preparations from cultures were Gram negative, although a few Grampositive forms were sometimes seen. They were non-motile at $22^{\circ} \mathrm{C}$. and $37^{\circ} \mathrm{C}$. Encapsulation was demonstrated by the Giemsa and Kirkpatrick methods. Aerobic growth was readily obtained on nutrient agar, horse blood agar, and MacConkey's bile-salt agar but not on Hoyle's tellurite medium. There was no growth anaerobically on horse blood agar or in Brewer's thioglycollate broth. The organisms failed to liquify gelatine or Loeffler's serum medium and were non-chromogenic on the latter. Catalase and ammonia were produced in peptone water. Indole, oxidase, and acetylmethyl-carbinol were not produced. Potassium nitrate was not converted to nitrite, nor urea to ammonia. The methyl red reaction was negative and citrate was not utilized. Acid only was produced from the pentoses arabinose and xylose, but not from rhamnose. From the hexoses, acid from mannose only was obtained but no splitting of glucose, fructose, or galactose was demonstrated. The organisms failed to ferment the disaccharides maltose, sucrose, lactose, and trehalose; the trisaccharide raffinose; the polysaccharide inulin; the alcohols dulcitol, mannitol, sorbitol, and adonitol as well as the glycosides salicin and aesculin.

The strains were sensitive to neomycin, erythro- $\frac{\vec{s}}{5}$ mycin, polymyxin B, framycetin, and colomycin but insensitive to chloromycetin, nitrofurantoin, novo- $\frac{-}{0}$ biocin, oleandomycin, streptomycin, tetracycline, $\frac{\overline{\bar{D}}}{\overline{2}}$ ristocetin, vancomycin, and penicillin, including $\widehat{\widehat{D}}$ D-alpha-aminophenylacetamido penicillanic acid and methicillin.

SEROLOGICAL INVESTIGATION A rabbit was injectedintravenously on three successive days of each of three weeks with a suspension of the Mima sp.응 isolated from case 1 . The organisms were administered in the live state, and, after the ninth $\vec{\sigma}$ injection, the serum was collected, preserved with merthiolate and stored in the deep freeze.

Doubling dilutions of this serum were made and? to these were added live suspensions of the twostrains of Mima. Agglutination was allowed to taken place for four hours at $55^{\circ} \mathrm{C}$. then overnight at roome temperature. The homologous strain was agglutinated to a dilution of 1 in 2,048 of the antiserum and the second strain to 1 in 8,192 .

\section{COMPARISON OF MIMA STRAINS, MORAXELLA, AND BACTERIUM ANITRATUM}

The investigations of de Bord (1943), Deacon (1945) Sorrell and White (1953), and Schuldberg (1953)ब would lead one to regard the tribe Mimeae as $a_{0}^{\overrightarrow{0}}$ group of organisms with essential biochemical 3 characteristics which show considerable variation, e.g., they may or may not (1) produce oxidase? (2) utilize citrate, (3) give a methyl red reaction (4) reduce nitrates to nitrites, (5) produce pigment, and (6) be haemolytic on blood agar.

Despite de Bord (1943) who stated that oxidased production by Mima spp. was variable, we find? Henriksen (1952) suggesting that Mima polymorpha var. oxidans was in fact a Moraxella because of resemblances to Moraxella in its production of oxidase and lack of saccharolytic properties.

In 1948, Schaub and Hauber described a group of ô organisms which has become known as Bacterium (or Achromobacter) anitratum, and in 1949 Stuart, Formal, and McGann described a group of bacteria $\omega$ which they named the B5W group. In 1950, Ferguson and Roberts suggested that these groups were members of the same species, although it must bees pointed out that the B5W group hydrolyses urea and does not give the methyl red reaction, whereas: Schaub and Hauber state that their group gives the methyl red reaction and hydrolyses urea. Ewing (1949) suggested that this $B$. anitratum B5W group was related to the tribe Mimeae. 
Now that the importance of $B$. anitratum is recognized as a cause of meningitis in this country and now that we are recording the appearance of Mima spp., it seemed a suitable time to attempt to establish if there were any relationship between these groups.

Four strains of B. (Achromobacter) anitratum were obtained from the National Collection of Type Cultures, London, and a comparison was made between their biochemical properties and those of our two strains of Mima. At the same time one strain each of Moraxella lacunata, bovis, and liquifaciens were obtained from the same source. The comparative results are set out in Table I.

TABLE I

COMPARISON OF PROPERTIES OF BOTH STRAINS OF MIMA AND OF B. ANITRATUM AND MORAXELLA SPP.

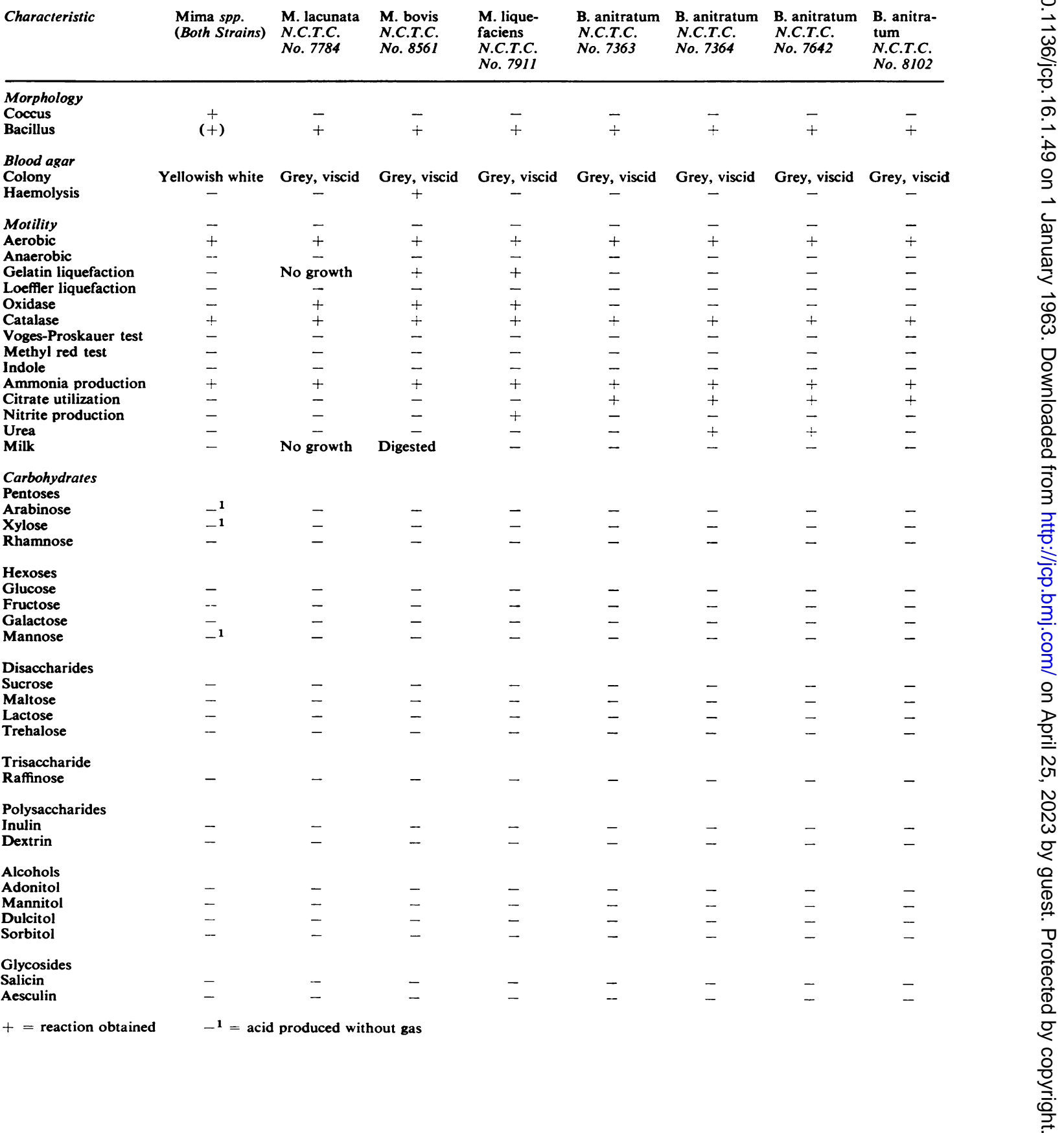


Suspensions of the four strains of $B$. anitratum were now agglutinated with the antiserum prepared against the first strain of M. polymorpha, as described above. After noting the results, the serum was now absorbed by aliquots of each of the four strains of $B$. anitratum till absorption was complete. The titre of the serum was now re-estimated by agglutinating suspensions of the homologous strain of Mima. The results are shown in Table II. It can be seen from these results that $B$. anitratum is unrelated to $M$. polymorpha.

\section{TABLE II}

RELATIONSHIP OF B. ANITRATUM TO M. POLYMORPHA

\begin{tabular}{|c|c|c|c|c|c|}
\hline & \multicolumn{2}{|c|}{ Mima polymorpha } & \multicolumn{3}{|c|}{ B. anitratum } \\
\hline & Case 1 & 7363 & 7364 & 7462 & 8102 \\
\hline $\begin{array}{l}\text { Unabsorbed serum } \\
\text { Absorbed serum }\end{array}$ & $\begin{array}{c}2,048^{1} \\
0\end{array}$ & $\begin{array}{r}128 \\
1,024\end{array}$ & $\begin{array}{r}256 \\
1,024\end{array}$ & $\begin{array}{r}256 \\
1,024\end{array}$ & $\begin{array}{r}0 \\
1,024\end{array}$ \\
\hline
\end{tabular}

${ }^{1}$ Titre is expressed as the reciprocal of the final dilution giving complete agglutination of the bacterial suspensions.

The paucity of biochemical properties of Mima and the variability of its positive attributes raises difficulty in classification. For example, as Gramnegative cocci are rare in nature, being confined to the genus Neisseria, the new tribe Mimeae and the genus Lampropedia (which is not recognized in Bergey's manual), it might be thought that organisms of the tribe Mimeae are related to Neisseria as several of the species in the latter genus are able to grow at $22^{\circ} \mathrm{C}$. and on nutrient agar in a similar manner to Mima; and while it is typical of species belonging to the genus Neisseria that they produce oxidase, several strains of Mima have been noted to do so also.

The features which appear to differentiate Mima from $B$. anitratum are not sufficiently definite. Some strains of $B$. anitratum hydrolyse urea but this is variable. The strains of $B$. anitratum examined in $\frac{0}{5}$ this investigation can utilize citrate as the sole음 source of carbon for growth whereas this is not $a \Rightarrow$ feature of Mima; but as stated above, Deacon (1945) showed that some strains of Mima show this feature. Also while the four strains of $B$. anitratum studied did not ferment glycosides, alcohols, or carbo- $\frac{\omega}{D}$ hydrates (with the possible exception of glucose in $\mathbb{D}$ one instance) and our strains of Mima did ferment $\%$ certain carbohydrates, it is said that typical or- $\overrightarrow{0}$ ganisms of the Mima group also do not ferment carbohydrates.

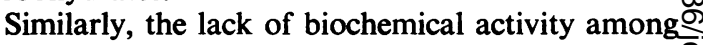
the organisms of the genus Moraxella inevitably? causes them in this respect to resemble the relatively $\vec{\sigma}$ inert Mima, but this is no evidence of relationship.-

There is no doubt that the strains of $B$. anitratum ${ }_{0}$ and Moraxella studied were all bacilli, by whicho they are distinguished from the strains of $\mathrm{Mima}_{-}$ since the latter were all cocci with only slighte tendency to bacillary morphology. Although it is? usually unsafe to rely on morphological appearances@ in identifying an organism, they may be helpful in instances such as this.

\section{REFERENCES}

Deacon, W. E. (1945). J. Bact., 49, 511.

De Bord, G. G. (1939). Ibid., 38, 119.

- (1943). J. Lab. clin. Med., 28, 710.

- (1948). J. Bact., 55, 764.

De Torregrosa, M. Vda., and Ortiz, A. (1961). J. Pediat., 59, 35. Ewing, W. H. (1949). J. Bact., 57, 659.

Faust, J., and Hood, M. (1949). Amer. J. clin. Path., 19. 1143.

Ferguson, W. W., and Roberts, L. F. (1950). J. Bact., 59, 171.

Henriksen, S. D. (1952). J. gen. Microbiol., 6, 318.

Pike, R. M., Schulze, M. L., and McCullough, M. (1951). Amer. J clin. Path., 21, 1094

Schaub, I. G., and Hauber, F. D. (1948). J. Bact., 56, 379.

Schuldberg, I. I. (1953). Amer. J. clin. Path., 23, 1024.

Sen, B. B. (1936). J. Bact., 32, 293.

Sorrell, W. B., and White, L. V. (1953). Amer. J. clin. Path., 23, $134 \stackrel{\circ}{\circ}$

Stuart, C. A., Formal, S., and McGann, V. (1949). J. infect. Dis., 84그. 235.

Townsend, F. M., Hersey, D. F., and Wilson, F. W. (1954). LI.S armed Forces med. J., 5, 673. 